\title{
Effect of food addition on the reproductive intensity and timing of both sexes of an intertidal crab
}

\author{
Tae Won Kim ${ }^{1,2, *}$, John H. Christy ${ }^{2}$, Jade R. Rissanen², Pablo D. Ribeiro ${ }^{3,4}$, Jae C. Choe \\ ${ }^{1}$ Hopkins Marine Station of Stanford University, 120 Oceanview Blvd., Pacific Grove, California 93950, USA \\ ${ }^{2}$ Smithsonian Tropical Research Institute, Apartado 0843-03092, Balboa, Ancon, Panama \\ ${ }^{3}$ Departamento de Biología, Universidad Nacional de Mar del Plata, Argentina \\ ${ }^{4}$ Consejo Nacional de Investigaciones Científicas y Técnicas (CONICET), Argentina \\ ${ }^{5}$ Department of Life Sciences, Ewha Womans University, Seoul 120-750, Korea
}

\begin{abstract}
Males and females of most animals time reproduction and synchronize their reproductive activity to maximize lifetime fitness. When food is abundant, however, the 2 sexes may time investments in reproduction differently due to sexual differences in how energy limits reproductive success. Many intertidal animals have reproductive cycles with semilunar or lunar periods timed to coincide with a certain phase of the tidal amplitude cycle when offspring survive best. Given an optimal time to breed, well-fed females may increase their investment in offspring but not change when they breed, while males may invest more both before and after the mating peak. We explored this possibility by feeding a mixed-sex population of the fiddler crab Uca terpsichores in field enclosures over 2 sequential trials of 1 mo each. Food addition increased male courtship intensity, particularly in the latter part of the semilunar reproductive cycles, but did not change the peak days of reproductive activity. Food addition had no consistent effects on female mate-searching intensity or reproductive timing during either month-long trial. These results suggest that female reproductive cycles and their timing do not result from semilunar variation in food. However, since females breed at most once a month, the trials may not have been of sufficient duration to reveal an effect of food on female reproductive investment. Previous studies suggest that semilunar variation in predation on larvae is the most important factor regulating reproductive timing by both sexes. Our results indicate that additional food also influences the schedule of male reproductive investment.
\end{abstract}

KEY WORDS: Reproductive timing $\cdot$ Intertidal animal $\cdot$ Tidal rhythm $\cdot$ Food addition $\cdot$ Fiddler crab

\section{INTRODUCTION}

Reproductive timing is a common feature of the life histories of both animals (see e.g. Christy 1978, Siikamäki 1998, Mysterud et al. 2008) and plants (e.g. Weatherhead 2005, Alexandre et al. 2006, Sletvold \& Grindeland 2007). Most organisms time reproduction and synchronize their reproductive activity to maximize lifetime fitness under prevailing conditions (Cohen 1976, Ims 1990, Brommer et al. 2002). However, males and females may have different reproductive interests due to their unequal parental investment (Trivers 1972, Knowlton 1979). Because females typically invest more during each reproductive event than do males, they stand to lose more if they make timing errors. Therefore, females should time reproduction more precisely with respect to conditions affecting their own fitness and that of their offspring (Knowlton 1979, Alexander et al. 1997). Males, in contrast, should schedule investments to maximize their mating opportunities and fertilization rates (Alexander et al. 1997, Mysterud et al. 2008) and can be less sensitive to variation in environmental conditions.

Temporal variation in the availability of food can significantly affect reproductive timing. Experimental studies, primarily of vertebrates, have shown that females that are better fed begin seasonal breeding earlier and have increased reproductive success (e.g. 
Sydeman et al. 1991, Svensson \& Nilsson 1995, Brodmann et al. 1997, Siikamäki 1998, Rubenstein \& Wikelski 2003, Davis et al. 2005, but see Shultz et al. 2009). Earlier reproduction is thought to enhance food intake rates and the competitive ability of offspring. In contrast, the effects of increased food on male reproductive timing have received less attention. Models of condition-dependent sexual signals (Zahavi 1977, Iwasa et al. 1991) predict that the expression of male sexual characters increases with condition, which is determined in part by resource intake and allocation. This prediction has received considerable support (reviewed by Cotton et al. 2004). We can also expect that well-fed males may advance or extend their investment in sexual advertisement to increase their mating opportunities (Kim \& Choe 2003).

Many marine animals have semilunar or lunar reproductive cycles (see e.g. Christy 1978, Robertson et al. 1990, Morgan \& Christy 1994, 1995, Palmer 1995, deBruyn \& Meeuwig 2001, Skov et al. 2005). This common timing pattern is thought to promote larval survival by reducing predation rates during early dispersal (Christy 2003, 2007). Because male reproductive success ultimately is determined by female reproductive success (Kokko \& Jennions 2003, Shuster \& Wade 2003), the reproductive timing of males and females often coincides (Christy 1978, Palmer 1995).

Although intertidal animals adaptively time reproduction relative to the tidal cycles, variation in other environmental factors can affect the reproductive activity and rhythms of intertidal animals, and the effects may differ between the sexes. Variation in food availability is one such factor. For example, female grass shrimp had higher fecundity under higher food availability (Reinsel et al. 2001), and male fiddler crabs increased (Backwell et al. 1995) and advanced their reproductive activity to an earlier date (Kim \& Choe 2003) when they were given additional food. Because the sexes differ in how they allocate energy to reproduction, variation in energy intake due to changes in food availability may affect reproductive timing differently in males and females. Despite many studies showing the influence of food quality or quantity on reproduction of marine animals (e.g. Makino \& Ban 2000, Reinsel et al. 2001, Niehoff 2004, Yoneda \& Wright 2005), few studies have investigated the effect of food availability on reproductive timing by both sexes. In the present study we test if food availability differently affects the reproductive intensity and timing of males and females of the neotropical intertidal fiddler crab Uca terpsichores. This species has a semilunar reproductive rhythm, as do other fiddler crabs (Christy et al. 2001, 2003). Females release larvae near the time of the nocturnal high spring tides (J. H. Christy, P. R. Y. Backwell, J. R. Ris- sanen unpubl. data). Courtship and mating immediately precede ovulation and fertilization, which begin the approximately $2 \mathrm{wk}$ period of embryonic development. The timing of cycles of male courtship and female receptivity, which are nearly identical, may be determined by selection for the precise timing of larval release (Christy 2007) and may resist change due to variation in food availability or other environmental factors. However, studies of $U$. lactea in Korea found that food availability fluctuated with the semilunar cycle of tidal inundation and influenced both the timing and intensity of male courtship (Kim \& Choe 2003, Kim et al. 2004). This indicated a level of flexibility in reproductive investment by males that was not expected based only on selection for timing of larval release.

Our specific experimental predictions were as follows: When food is scarce, males should conserve energy and court only during the peak of female receptivity, when their chance of encountering a mate is greatest. When food is abundant and males are well fed, they should increase their mating opportunity by courting throughout the reproductive period, even early and late when the chance of encountering receptive females is low. The cost to well-fed males of courting when receptive females are rare would be relatively low. Courting on more days of the semilunar cycle might allow them to mate more than once each breeding period (e.g. Christy 1982, deRivera 2003). Hence, well-fed males may show a semilunar cycle with broader reproductive activity periods. In addition, there should be an increase in the proportion of males in a local population that court each day throughout the reproductive cycle. In contrast, because incubation takes about $2 \mathrm{wk}$, females can breed at most once in each semilunar period; reproductive timing for larval release during optimal tidal conditions for larval survival would be still be important so additional food may not affect female reproductive timing. However, the number of receptive females may increase in the presence of supplemental food because the nutritional condition of females would become better and more individuals might be ready to breed each cycle (Fig. 1).

\section{MATERIALS AND METHODS}

Study site and species. This study was conducted from 1 March to 25 May 2004 on a sand beach $\left(8^{\circ} 54^{\prime} \mathrm{N}\right.$, $\left.79^{\circ} 31^{\prime} \mathrm{W}\right)$ on the western shore of Culebra Island located on the Amador Causeway, which forms the western edge of the Pacific entrance to the Panama Canal. The study spanned the mid-April transition between the dry and wet seasons. The maximum tidal 


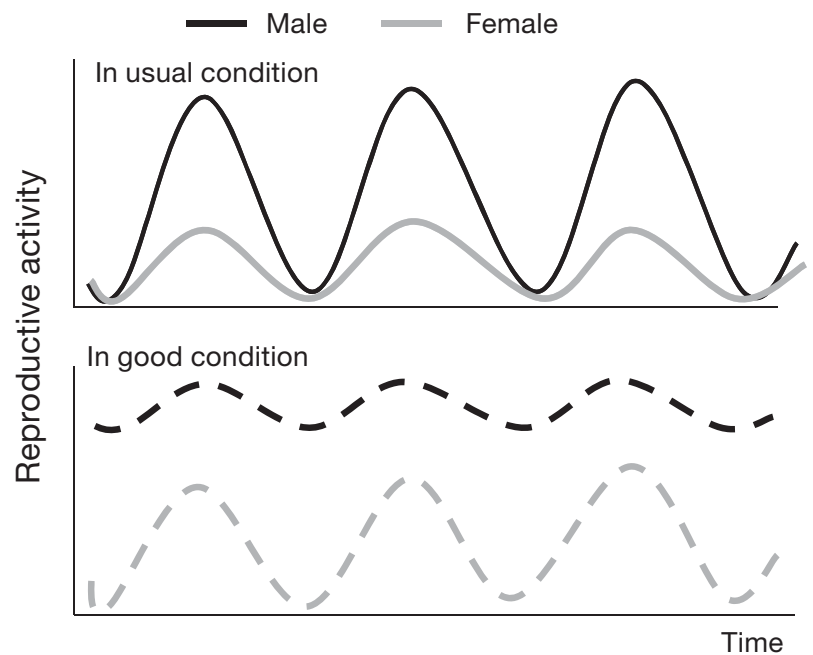

Fig. 1. Uca terpsichores. Hypothetical model of the effect of food on male and female reproductive activity

range was $5.8 \mathrm{~m}$ during the April full moon spring tides, and the minimum range was about $1.9 \mathrm{~m}$ during the April neap tides (first and last quarter moons). The mixed-sex population of Uca terpsichores on this beach occupies about $40 \%$ of the upper intertidal zone (4 $\mathrm{m}$ range perpendicular, $60 \mathrm{~m}$ range parallel to the water's edge). There are about 5000 to 7000 adult crabs (20 to 30 crabs with all sizes $\mathrm{m}^{-2}$ ) on this beach (J. H. Christy unpubl. data). Soon after their habitat is exposed to the air by the receding tide, crabs emerge from their burrows, feed, and interact socially on the surface. The activity period is longest (about $8 \mathrm{~h}$ ) on days with mid-day low tides during the spring tides. Crabs mate only underground in males' burrows. Females seek mates by moving sequentially between courting males, who compete to attract females by claw waving and by building an arching mound of sand called a hood at their burrow opening. Few crabs emerge from their burrows when the tide is low before about 08:00 $\mathrm{h}$ and after about 17:00 $\mathrm{h}$, or when it is raining.

Experimental setup. On a densely populated area of the beach, we marked 2 rows (parallel to the water's edge) of 9 plots $(1 \times 1.5 \mathrm{~m})$. Plots were spaced $1 \mathrm{~m}$ apart. The plots in each row were divided into 3 groups of 3 plots each. In each group 1 plot was bounded by twine attached to $0.5 \mathrm{~m}$ long metal stakes at the corners and was left open while enclosures were placed on the other 2 plots. The location of the open plot in each group was chosen at random by drawing lots. We built the $1 \times 1.5 \times 0.3 \mathrm{~m}$ enclosures using frames of steel angle and wire mesh $(0.3 \mathrm{~cm}$ square openings) for the sides. The enclosures were open on the top and bottom. They were buried so that $15 \mathrm{~cm}$ of the mesh walls extended above the sand surface. Fiddler crab burrows usually have a single opening (see e.g. Christy \& Schober 1994), so it is very unlikely that crabs that emerged inside the enclosures escaped by digging under the walls to the outside. In addition, previous studies using very similar enclosures (Backwell et al. 1995, deRivera et al. 2003) have shown they are effective barriers to crab movements for periods of at least 2 mo. The open plots served as controls for enclosure effects. For $4 \mathrm{~d}$ before adding food, crabs were observed to determine if there were differences in their behavior between enclosures and open plots. The observation began on 13 March in the last quarter of the lunar period.

Food addition. As soon as the receding tide exposed the experimental area, and before the crabs emerged on each day of the experiment, $5 \mathrm{~g}$ of food (Tetramin fish flake) mixed with 1.51 seawater was added to 6 of the 12 enclosures, 1 in each group of 3 . This level of food addition has been used in other studies (Backwell et al. 1995, Kim \& Choe 2003, Kim et al. 2008) and has produced positive effects on crab behavior that are consistent with increased nutrition. Seawater (1.5 l) without food was added to each of the other 6 enclosures and to the 6 control plots. The food was added daily for 2 semilunar cycles so that the additional nutrition would have a cumulative effect on crab condition (Backwell et al. 1995)

After 2 semilunar cycles, the enclosures were damaged by wave action. The enclosures were repaired, moved to an adjacent high-density area, and a second feeding experiment was done. Due to the dimensions of the new area and the distribution of the crabs within it this time, we made 3 rows of 6 plots $(1 \times 1.5 \mathrm{~m})$ and put 2 enclosures at randomly chosen locations in each row. The previous experimental procedure was then repeated over 2 additional fortnightly cycles. However, for lack of time, and because we found no differences between plots in the first experiment (see 'Results'), we did not observe the crabs for $4 \mathrm{~d}$ before we began to add food. During $3 \mathrm{~d}$ (30 March to 1 April) and $5 \mathrm{~d}$ (27 April to 1 May) between the 2 fortnightly cycles, we did not observe the crabs because the low tides were too early or late in the day for crabs to emerge, and the high tides were too low to fully cover the area with burrows, a condition that also suppresses crab surface activity (Kim et al. 2004).

Observations. We observed the crabs through binoculars while seated on a $1.2 \mathrm{~m}$ high observation platform positioned about $2 \mathrm{~m}$ down-beach from the closest enclosure and $10 \mathrm{~m}$ from the most distant one. Every hour, from $2 \mathrm{~h}$ before to $3 \mathrm{~h}$ after the time of low tide, 2 observers, starting from opposite directions, recorded the number of males and females on the surface, the number of waving (courting) males, 
the number of sand hoods, and the number of matesearching females in each enclosure and open plot. The greater of the 2 observers' values was used for each variable in each enclosure and open plot. Although the number of sand hoods usually gives an accurate measure of courtship intensity (Christy et al. 2001, 2003), during our experiment from March to May, very few hoods were built on Culebra Beach. Therefore, the number of claw-waving (courting) males was used as the measure of courtship activity in each enclosure or plot. The total number of matesearching females (identifying criteria in Christy et al. 2002) seen each hour in each enclosure or plot was the measure of female reproductive activity.

Statistical analysis. To test for an effect of food addition on crab reproductive activity, a 2-way repeatedmeasures ANOVA was used treating the values on each day for each enclosure as the repeated measures. Because the activity of crabs can vary between treatments, we also calculated the proportion of waving males or mate-searching females relative to the total number of males or females active on the surface, respectively. Since the proportional data are nonnormally distributed, they were arcsine square root transformed. We did not find any significant difference between the counts and the proportional measurements. We, therefore, present the proportional measurements in the 'Appendix' but not in the 'Results' here. When the assumption of equal between-group correlations and group variances ('sphericity') was violated, we applied the Huynh-Feldt for correction of p-values (Zar 1999, p 259).

Circular distributions of the number of courting males and mate-searching females were also used to determine if there were significant differences in the temporal distributions of reproductive activity. Our observations gave data for 4 fortnightly cycles distributed across 15 daily angular intervals of $24^{\circ}$. The angular vectors of the number of courting males and matesearching females within same treatment were pooled in each cycle. A Rayleigh test was used to determine whether reproductive activity was uniformly distributed during each cycle. A Watson-Williams F-test was used to determine if there is a significant difference in the mean vectors between treatments and sexes (Zar 1999, p 625-630). We designated the days (from when we began adding food in each experiment) with the maximum number of courting males and mate-searching females in each experiment as the peak days of reproductive activity. A Kruskal-Wallis $H$-test was used to determine if food addition influenced the peak days of reproductive activity. We used SPSS software ver. 12.0 for ANOVA tests and Oriana software (RockWare) ver. 2.0 for circular statistics. Summary statistics are presented as means $\pm \mathrm{SD}$.

\section{RESULTS}

\section{Intensity of reproductive activity}

During the $4 \mathrm{~d}$ before we added food there was no difference in the number of males (repeated-measures ANOVA; Food: $F_{2,15}=2.182, \mathrm{p}=0.147 ;$ Food $\times \mathrm{d}: F_{6,45}=$ 1.456, $\mathrm{p}=0.215$ ) or females (Food: $F_{2,15}=2.581, \mathrm{p}=$ 0.109 ; Food $\times$ Days: $F_{3.848,28.862}=0.374, \mathrm{p}=0.818$ ) active on the surface between treatments. The number of waving males $\left(F_{2,15}=2.656, \mathrm{p}=0.103\right)$ and non-courting (feeding) males $\left(F_{2,15}=0.588, p=0.568\right)$ also was not different between treatments.

During the first experiment, neither the number of males $\left(F_{2,15}=1.519, \mathrm{p}=0.251\right)$ nor females $\left(F_{2,15}=\right.$ $2.468, p=0.118$ ) active on the surface differed significantly between treatments. During the first $4 \mathrm{~d}$ of the experiment, the number of courting males appeared lower in the enclosures with additional food compared to those with natural food levels (Fig. 2). This might be because of the higher level of feeding activity of males in food-supplemented plots than in any other treatments $\left(F_{2,15}=4.65, \mathrm{p}=0.027\right)$. After $4 \mathrm{~d}$, however, the number of claw-waving males in the food-supplemented enclosures increased and then exceeded the number in the other treatments (Fig. 2). Overall, there were significantly more waving males (Tables 1 \& A1) and fewer feeding males (Food: $F_{2,15}=3.893, \mathrm{p}=0.04$; Food $\times$ Days: $F_{50,375}=2.099, \mathrm{p}=0.07$ ) in the food-added enclosures. Post hoc comparisons indicated that food addition not enclosures influenced the number of waving males (Tukey's Honestly Significant Difference [HSD] test; food-supplemented vs. non-supplemented: $\mathrm{p}<0.001$; non-supplemented vs. natural: $\mathrm{p}=0.314$ )

Table 1. Uca terpsichores. Repeated measures ANOVA results for experimental treatment effect on the number of waving males

\begin{tabular}{|lrrrc|}
\hline Source & MS & df & $F$ & $p$ \\
\hline First trial & & & & \\
Within plots & & & & \\
$\quad$ Day & 98.97 & 14.40 & 31.55 & $<0.0001$ \\
$\quad$ Day $\times$ Food treatment & 9.73 & 28.80 & 3.10 & $<0.0001$ \\
$\quad$ Error & 3.14 & 216.01 & & \\
Between plots & & & & \\
$\quad$ Food treatment & 182.25 & 2 & 10.87 & 0.001 \\
$\quad$ Error & 16.77 & 15 & & \\
& & & & \\
Second trial & & & & \\
Within plots & 33.07 & 10.80 & 4.17 & $<0.0001$ \\
$\quad$ Day & 9.75 & 21.60 & 1.23 & 0.256 \\
$\quad$ Day $\times$ Food treatment & 7.92 & 64.80 & & \\
Error & & & & \\
Between plots & 75.57 & 2 & 6.79 & 0.029 \\
$\quad$ Food treatment & 11.12 & 6 & & \\
$\quad$ Error & & & & \\
\hline
\end{tabular}



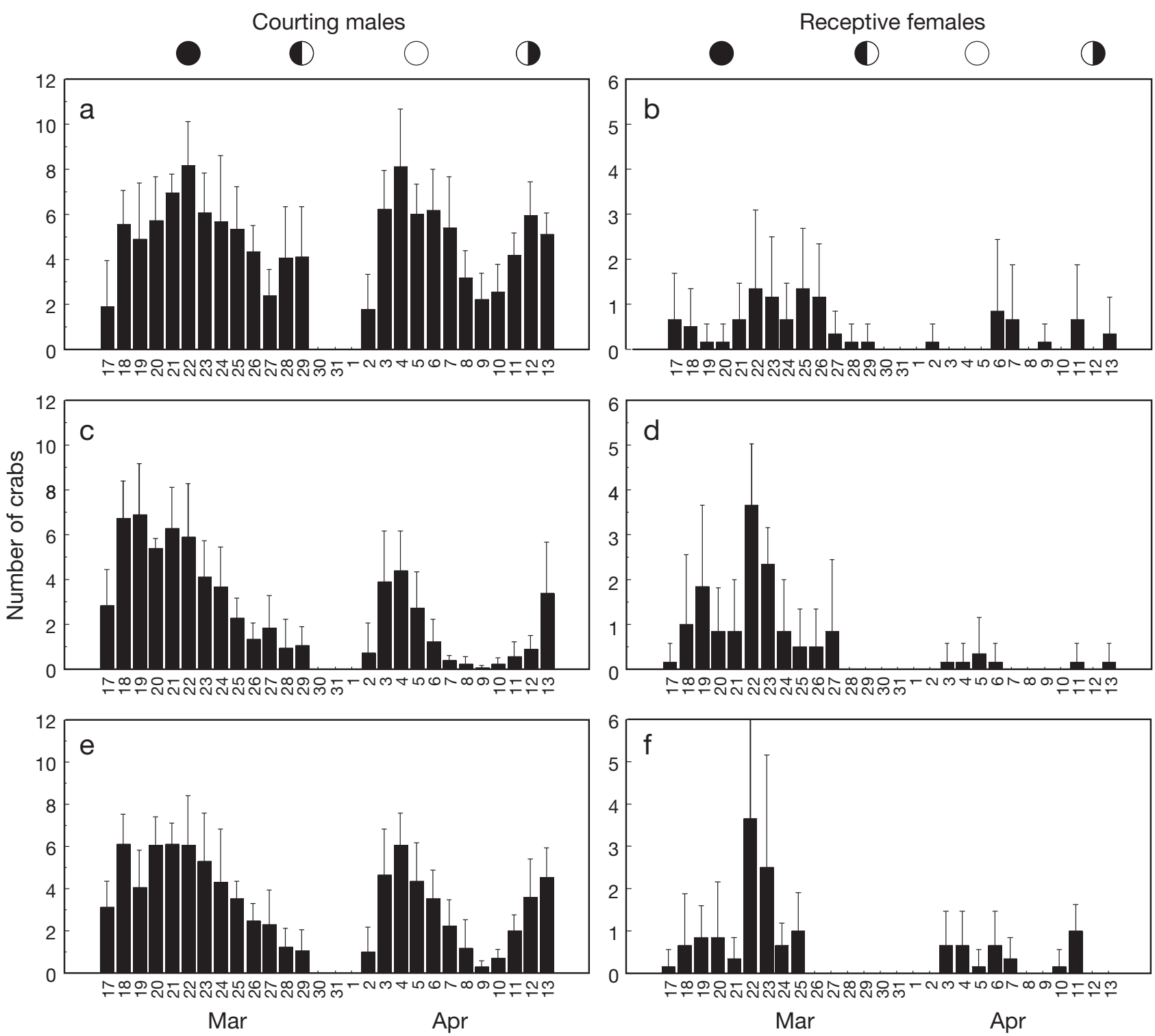

Fig. 2. Uca terpsichores. Distribution of the number (mean $\pm \mathrm{SD}$ ) of courting males and receptive females under (a,b) enclosed, food-supplemented, (c,d) enclosed, non-supplemented, and (e,f) open, natural conditions during the first trial. $\bigcirc, 0$, and $\bigcirc$ represent new moon, first quarter, full moon, and last quarter, respectively

and feeding males (food-supplemented vs. nonsupplemented: $\mathrm{p}=0.037$; non-supplemented vs. natural: $\mathrm{p}=0.216)$.

In contrast, the number of mate-searching females did not differ between treatments (Fig. 2, Table 2) and the proportion of mate-searching females (Table A2) did not differ between treatments. However, an interaction between food supplementation and days showed that there was a decrease in the number of mate-searching females as the cycle advanced (Tables 2 \& A2).

In the second experiment, there was no significant difference in the number of males $\left(F_{2,15}=1.022, \mathrm{p}=\right.$
$0.384)$ or females $\left(F_{2,15}=0.622, \mathrm{p}=0.550\right)$ on the surface between treatments. Both the number of clawwaving males (Fig. 3, Table 1) and the proportion of waving males (Table A1) were higher in the foodadded enclosures. Post hoc comparisons confirmed that food addition increased the number of clawwavers (Tukey's HSD; food-supplemented vs. nonsupplemented: $\mathrm{p}=0.025$; non-supplemented vs. natural: $\mathrm{p}=0.456)$. Again, the number of mate-searching females did not differ between treatments (Fig. 3, Table 2). The proportion of mate-searching females also did not differ between treatments (Table A2). 
Table 2. Uca terpsichores. Repeated measures ANOVA results for experimental treatment effect on the number of mate-searching females

\begin{tabular}{|lrrrc|}
\hline Source & MS & df & \multicolumn{1}{c|}{$F$} & $\mathrm{p}$ \\
\hline First trial & & & & \\
Within plots & & & & \\
$\quad$ Day & 15.34 & 12.13 & 10.659 & $<0.0001$ \\
$\quad$ Day $\times$ Food treatment & 2.34 & 24.26 & 1.627 & 0.039 \\
$\quad$ Error & 1.44 & 181.95 & & \\
Between plots & & & & \\
$\quad$ Food treatment & 0.76 & 2 & 0.41 & 0.668 \\
$\quad$ Error & 1.84 & 15 & & \\
Second trial & & & & \\
Within plots & & & & \\
$\quad$ Day & 12.23 & 12.71 & 7.213 & $<0.0001$ \\
$\quad$ Day $\times$ Food treatment & 1.57 & 25.43 & 0.930 & 0.565 \\
$\quad$ Error & 1.70 & & & \\
Between plots & & & & \\
$\quad$ Food treatment & 3.44 & 2 & 0.518 & 0.606 \\
$\quad$ Error & 6.64 & 15 & & \\
\hline
\end{tabular}

\section{Reproductive timing}

The addition of food did not affect the peak days of male reproductive activity or the interval between the peak days (Table 3 ). The female reproductive peak days and the interval between the peak days also were not affected by food addition. However, the second peak day of female reproductive activity in the first experiment was delayed (Table 4). The number of mate-searching females was very low, however, making it difficult to judge whether this was a real effect of food addition or not.

When the data on each day were converted to angles, there were consistent significant differences in the mean vectors of the number of courting males between treatments, except for the fourth cycle. In the first cycle, the angle of the mean vector of courting males in food-supplemented enclosures was larger than that in any other treatment (food-supplemented: $186^{\circ} \pm 83^{\circ}$; non-supplemented: $160^{\circ} \pm 87^{\circ}$; natural: $176^{\circ} \pm 80^{\circ}$; Rayleigh test, $\mathrm{p}<0.0001$ in all treatments; Watson-Williams $F$-test: $F_{2,1666}=10.597, \mathrm{p}<0.0001$; Fig. 4a). There also were consistent differences between treatments in the second cycle (food-supplemented: $133^{\circ} \pm 91^{\circ}$; non-supplemented: $78^{\circ} \pm 88^{\circ}$; natural: $111^{\circ} \pm 92^{\circ}$; Rayleigh test, $\mathrm{p}<0.01$ in all treatments, $F_{2,1159}=24.628, \mathrm{p}<0.0001$, Fig. $4 \mathrm{~b}$ ) and third cycle (food-supplemented: $143^{\circ} \pm 80^{\circ}$; non-supplemented: $121^{\circ} \pm 76^{\circ}$; natural: $127^{\circ} \pm 78^{\circ}$; Rayleigh test; $\mathrm{p}$ $<0.0001$ in all treatments; $F_{2,1248}=7.48, \mathrm{p}<0.0001$, Fig. $4 \mathrm{c})$. Although the distribution of courting males is quite uniform except in the non-supplemented plots in the fourth cycle (food-supplemented: $142^{\circ} \pm 117^{\circ}$; non- supplemented: $34^{\circ} \pm 131^{\circ} ;$ natural: $129^{\circ} \pm 128^{\circ}$; Rayleigh test; all p $=\mathrm{ns}$ [not significant], except for non-supplemented: $\mathrm{p}<0.001)$, the mean vector angles was significantly different between treatments $\left(F_{2,1228}\right.$ $=40.14, \mathrm{p}<0.0001$, Fig. 4d). Pair-wise comparisons confirmed that there were significant differences between food-supplemented and non-supplemented plots in all cycles (all $\mathrm{p}<0.001$ ). In contrast, the mean vector angles of female reproductive activity in the food-supplemented plots was not greater than in the non-supplemented plots except during the first cycle (Watson-Williams F-test; first cycle, $F_{1,129}=9.88, \mathrm{p}=$ 0.002; all p = ns in the other cycles, Fig. 5)

\section{DISCUSSION}

Males and females responded differently to additional food. Food-supplemented males increased their courtship activity throughout their reproductive periods as expected. They courted more in the later part of the reproductive cycle. In contrast, well-fed females did not increase their reproductive activity: they decreased their mate-searching behavior in the first trial but showed no significant changes in the second trial. Backwell et al. (1995) also found that food supplementation increased male reproductive activity in the fiddler crab Uca beebei. However, the possible effects of food supplementation on female reproduction and on the timing of reproduction by both sexes were not measured.

Food supplementation did not affect the peak days of reproductive activity of either sex. Given the cycle in female sexual receptivity and the female-biased operational sex ratio (due to the much longer breeding period for females compared to males), males should court most when females are most abundant leading to synchrony in reproductive activity between the sexes. The single exception in this study was the delay in the second female semilunar reproductive peak during the first trial. This exceptional case seems to be related to the decreased number of mate-searching females at that time making estimates of the peak less robust. Although female reproductive activity was lower in enclosures without additional food, we found no evidence of an effect of food on the female reproductive level.

However, the mean vector of male courtship activity was delayed when food was added. Well-fed males evidently invested more in courtship in the later part of each cycle. This result differs from that found in the previous study of Uca lactea in Korea (Kim \& Choe 2003). The habitat at the study site was not inundated by tides about half of each cycle and became dry. At this time these deposit feeders could not feed on 

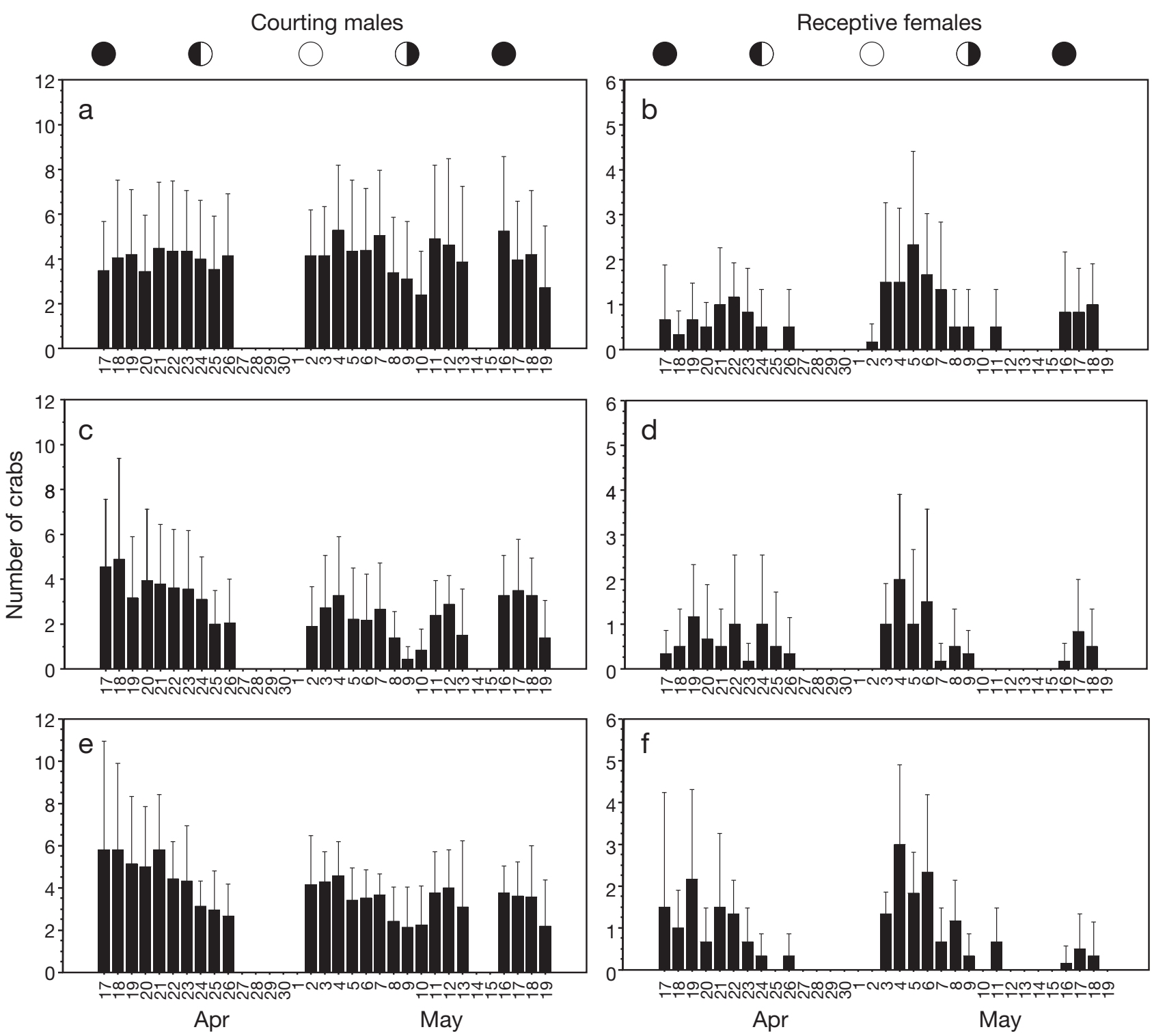

Fig. 3. Uca terpsichores. Distribution of the number (mean $\pm \mathrm{SD}$ ) of courting males and receptive females (right) under (a,b) enclosed, food-supplemented, (c,d) enclosed, non-supplemented, and $(\mathrm{e}, \mathrm{f})$ open, natural condition during the second trial. $, 0,0$, and represent new moon, first quarter, full moon, and last quarter, respectively

organic material contained in the sediment (Kim et al. 2004). The addition of food shifted the timing of male $U$. lactea reproductive activity earlier and increased the duration of activity (Kim \& Choe 2003). However, during the present study, the tide covered the crabs' habitat on all but 1 to $4 \mathrm{~d}$ each semilunar cycle, indicating that food was not as limiting as it was for U. lactea. We therefore predicted that well-fed male $U$. terpsichores would not change their reproductive timing but would extend courtship to include days when there were few females searching for mates. This prediction was partially fulfilled; when given extra food, males reached a peak at the same time as unfed males then extended courtship for longer in the later part of the cycle.

The increase in courtship activity by well-fed males in the later parts of cycles may reflect how males budget resources to courtship. When males first received additional food in each period, they may have invested in feeding rather than courting, reflecting the relative advantage of feeding and courting early in the cycle when few females are seeking mates. Thus males may have evolved a strategy to give priority to feeding to accumulate energy when food unexpectedly becomes available before a reproductive peak (Kim et al. 2008). This accumulated energy could be used to court more 
Table 3. Uca terpsichores. Male reproductive peak days (mean \pm SD), and the peak-to-peak interval in each trial in different food conditions. Peak day: day when the number of courting males was highest. H: Kruskal-Wallis test

\begin{tabular}{|c|c|c|c|c|c|c|}
\hline & & $\begin{array}{l}\text { Food- } \\
\text { supplemented } \\
(\mathrm{n}=6)\end{array}$ & $\begin{array}{l}\text { Non- } \\
\text { supplemented } \\
(\mathrm{n}=6)\end{array}$ & $\begin{array}{l}\text { Natural } \\
\text { condition } \\
(\mathrm{n}=6)\end{array}$ & $H$ & $\mathrm{p}$ \\
\hline \multirow[t]{3}{*}{ First trial } & First peak day & $5.67( \pm 0.52)$ & $5.17( \pm 0.98)$ & $5.67( \pm 1.37)$ & 0.484 & 0.626 \\
\hline & Second peak day & $19.50( \pm 1.23)$ & $18.67( \pm 0.52)$ & $18.67( \pm 0.52)$ & 2.049 & 0.163 \\
\hline & Peak interval (d) & $13.83( \pm 0.98)$ & $13.50( \pm 1.05)$ & $13.00( \pm 1.41)$ & 0.779 & 0.477 \\
\hline \multirow[t]{3}{*}{ Second trial } & First peak day & $1.83( \pm 2.14)$ & $18.00( \pm 1.67)$ & $17.67( \pm 1.86)$ & 2.726 & 0.097 \\
\hline & Second peak day & $18.83( \pm 1.26)$ & $19.30( \pm 2.28)$ & $19.33( \pm 1.63)$ & 0.600 & 0.561 \\
\hline & Peak interval (d) & $17.00( \pm 2.37)$ & $17.00( \pm 1.90)$ & $14.33( \pm 2.16)$ & 3.077 & 0.070 \\
\hline
\end{tabular}

vigorously during the peak of female receptivity and later in the cycles. Thus, male courtship and female receptivity rhythms could move slightly out of phase in a food-variable environment.

We predicted that the number of mate-searching females would increase when females received more food, or that females would begin breeding earlier. However, we found no evidence supporting either expectation. Because cages were destroyed by a storm, we were unable to apply the food treatment to the same individuals for 2 mo. Instead, we moved the experimental cages and conducted a second trial at another site with new crabs. Other species of fiddler crabs with similar ecologies breed at approximately 4 to 6 wk intervals (e.g. Uca pugilator) (Christy 1978). However, recent research using marked females in the field at a nearby site in Panama (K. Kerr unpubl. data) indicates that individual female $U$. terpsichores can breed more than once a month. In addition, it is likely that some females in the experimental plot had not just released larvae when the experiment began. Additional food may have allowed these females to begin breeding sooner than they might have otherwise. Although the duration of our food treatments in the 2 trials was not ideal, we believe that some food-supplemented females should have shown more mate searching, assuming that food increases condition and readiness to breed.

The result differs broadly from the general pattern for other animals in which well-fed females initiate breeding earlier or increase breeding frequency (see e.g. Sydeman et al. 1991, Svensson \& Nilsson 1995, Brodmann et al. 1997, Siikamäki 1998, Diaz \& Alonso 2003, Rubenstein \& Wikelski 2003, Davis et al. 2005, Nielsen \& Møller 2006, Varpe et al. 2007). This difference may be due to the importance of life history timing relative to the physical cycles in the intertidal zone. Female reproductive activity in fiddler and other crabs usually is scheduled so that larvae are released at high tide at night when they best escape their diurnal predators in shallow water and are most rapidly transported seaward to safer waters (Morgan \& Christy 1994, 1995, Christy 2003, Christy et al. 2003). The adaptive value of timing for early larval survival and

Table 4. Uca terpsichores. Female reproductive peak days (mean \pm SD), and the peak-to-peak interval in each trial in different food conditions. Peak day: day when the number of courting males was highest. $H$ : Kruskal-Wallis test

\begin{tabular}{|c|c|c|c|c|c|c|}
\hline & & $\begin{array}{c}\text { Food- } \\
\text { supplemented }\end{array}$ & $\begin{array}{c}\text { Non- } \\
\text { supplemented }\end{array}$ & $\begin{array}{c}\text { Natural } \\
\text { condition }\end{array}$ & $H$ & $\mathrm{p}$ \\
\hline \multirow[t]{3}{*}{ First trial } & First peak day & $\begin{array}{c}5.67( \pm 2.66) \\
(\mathrm{n}=6)\end{array}$ & $\begin{array}{c}6.00( \pm 1.27) \\
(\mathrm{n}=6)\end{array}$ & $\begin{array}{c}6.17( \pm 0.75) \\
(\mathrm{n}=6)\end{array}$ & 0.126 & 0.882 \\
\hline & Second peak day & $\begin{array}{c}23.80( \pm 2.28) \\
(\mathrm{n}=5)\end{array}$ & $\begin{array}{c}19.67( \pm 0.53) \\
(\mathrm{n}=3)\end{array}$ & $\begin{array}{c}21.20( \pm 1.92) \\
(\mathrm{n}=5)\end{array}$ & 4.399 & 0.043 \\
\hline & Peak interval (d) & $\begin{array}{c}17.20( \pm 2.78) \\
(\mathrm{n}=5)\end{array}$ & $\begin{array}{c}14.00( \pm 0.00) \\
(\mathrm{n}=3)\end{array}$ & $\begin{array}{c}15.00( \pm 2.24) \\
(\mathrm{n}=5)\end{array}$ & 2.193 & 0.160 \\
\hline \multirow[t]{3}{*}{ Second trial } & First peak day & $\begin{array}{c}5.17( \pm 0.98) \\
(\mathrm{n}=6)\end{array}$ & $\begin{array}{c}4.20( \pm 2.78) \\
(\mathrm{n}=5)\end{array}$ & $\begin{array}{c}4.92( \pm 4.91) \\
(\mathrm{n}=6)\end{array}$ & 0.393 & 0.682 \\
\hline & Second peak day & $\begin{array}{c}18.75( \pm 1.26) \\
(\mathrm{n}=6)\end{array}$ & $\begin{array}{c}19.30( \pm 2.28) \\
(n=5)\end{array}$ & $\begin{array}{c}19.33( \pm 1.63) \\
(\mathrm{n}=6)\end{array}$ & 0.209 & 0.814 \\
\hline & Peak interval (d) & $\begin{array}{c}13.58( \pm 2.01) \\
(\mathrm{n}=6)\end{array}$ & $\begin{array}{c}15.10( \pm 4.34) \\
(\mathrm{n}=5)\end{array}$ & $\begin{array}{c}14.42( \pm 2.20) \\
(\mathrm{n}=6)\end{array}$ & 0.372 & 0.696 \\
\hline
\end{tabular}



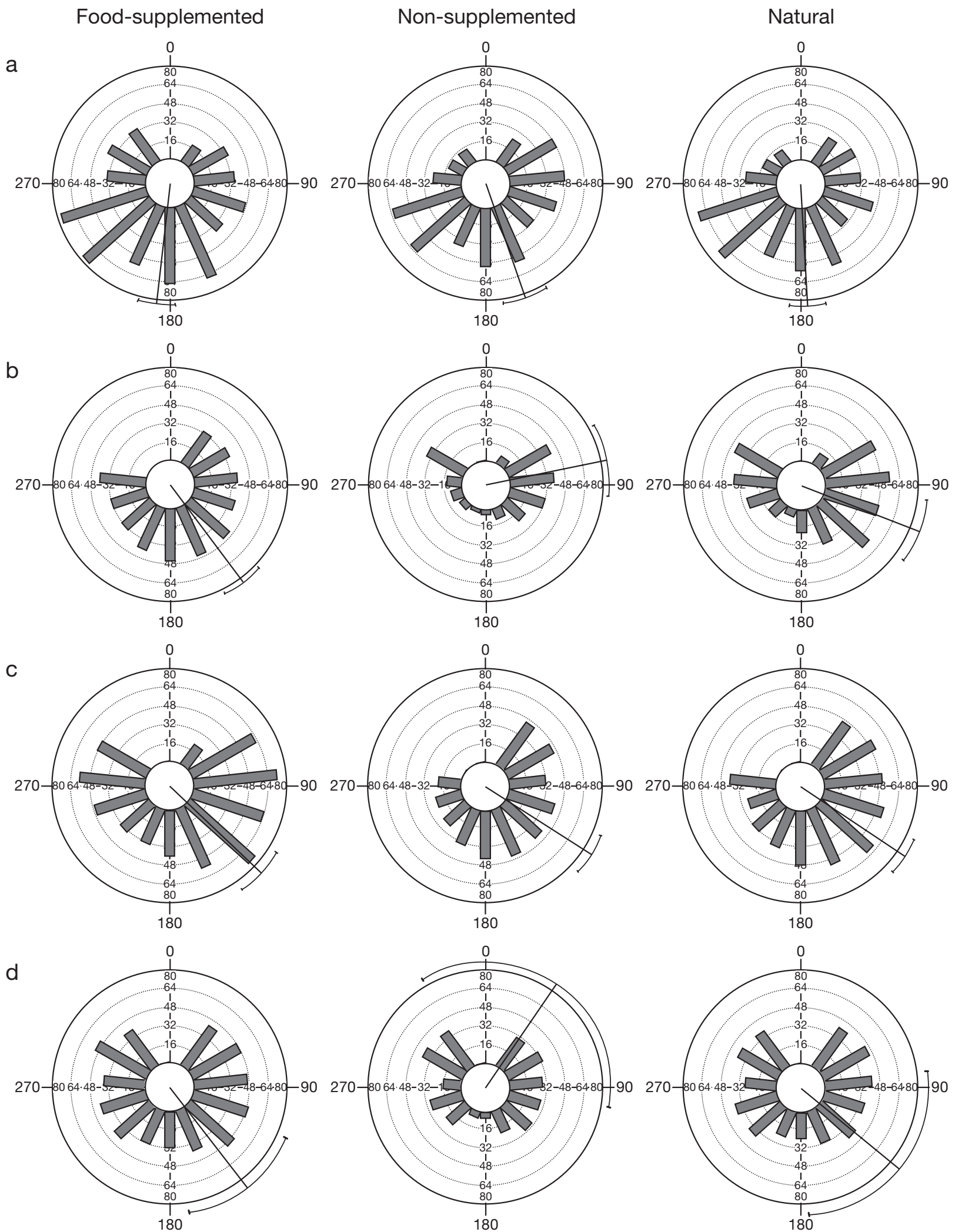

Fig. 4. Uca terpsichores. Angular distribution of male courtship activity in the (a) first, (b) second, (c) third and (d) fourth cycle. Zero degree corresponds to the first day of food supplementation within a $15 \mathrm{~d}$ cycle. The straight line from the center represents the mean vector; error bars from the mean vector represents $95 \%$ confidence interval for the mean vector 
Food-supplemented
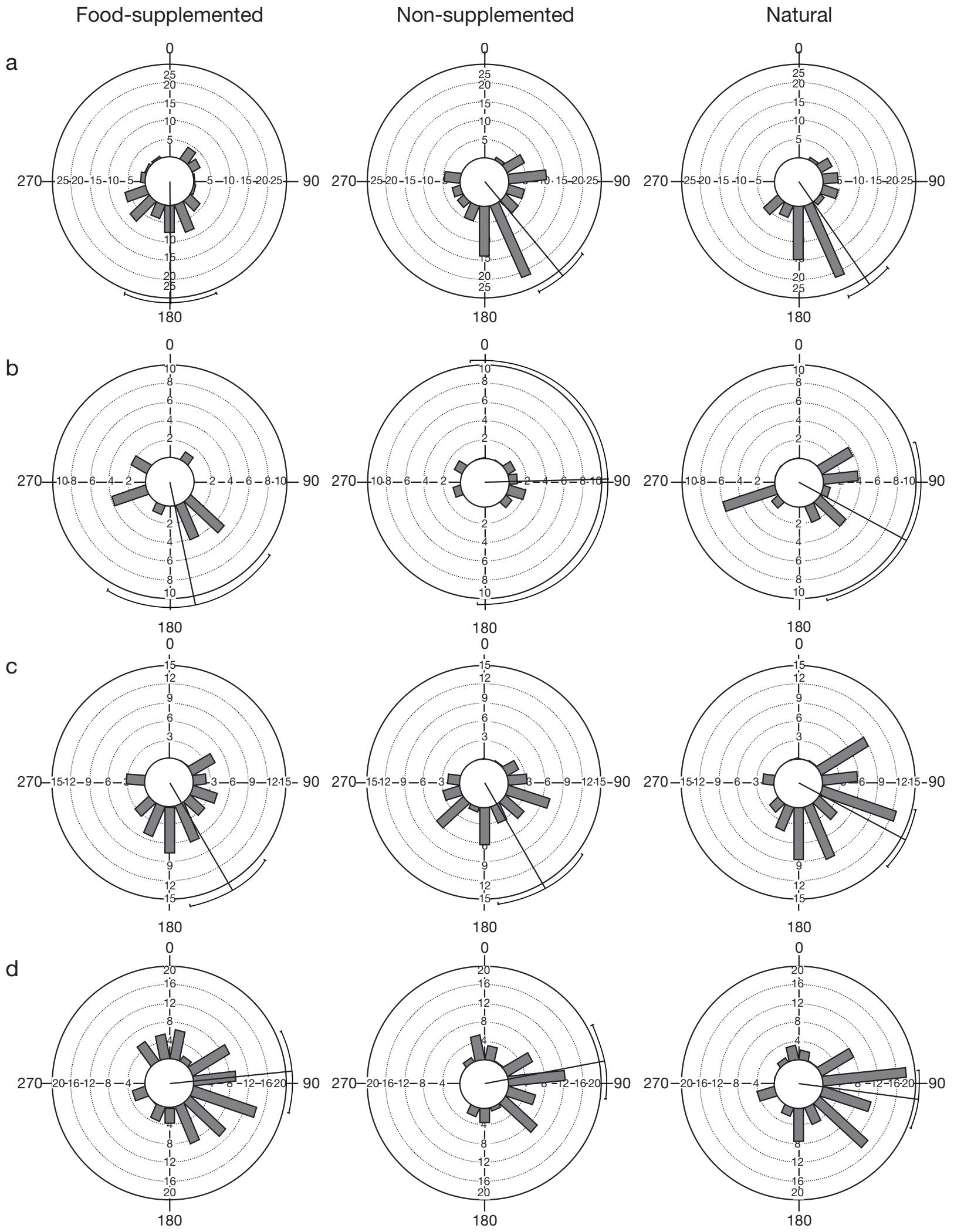

Fig. 5. Uca terpsichores. Angular distribution of female mate-searching activity in the (a) first, (b) second, (c) third and (d) fourth cycle. Zero degree corresponds to the first day of food supplementation within a $15 \mathrm{~d}$ cycle. The straight line from the center represents the mean vector; error bars from the mean vector represents $95 \%$ confidence interval for the mean vector 
favorable dispersal must override any possible advantage of changing timing in response to additional food.

In terms of allocation of energy reserves to reproduction, the sexes differed in their responses to food supplementation. When given additional food, males increased overall reproductive activity but females did not. This result may reflect sexual differences in the factors affecting reproductive success. Males should adopt behavior that maximizes their mating opportunities which are proportional to the rates that they encounter and court fertile females (Shuster \& Wade 2003). For females, however, reproductive output and offspring survival usually are the most important determinants of reproductive success. Although males spend time mate guarding, the time they allocate to offspring is much smaller than that of females. Males spend less than $3 \mathrm{~d}$ in their burrows guarding their mates until they oviposit and fertilize their eggs (Christy et al. 2001). In contrast, females spend about $17 \mathrm{~d}$ underground from the time they choose a mate until their eggs hatch and they release their larvae on a nocturnal high tide (J. H. Christy \& P. R. Y. Backwell unpubl. data). As in other animals, the strong sexual bias in parental investment may explain why the sexes responded differently to the addition of food. While wellfed males may increase their mating rates by courting more (Christy et al. 2001), well-fed females may invest their energy into producing larger clutches (e.g. Niehoff 2004). Females also may store sperms for months, giving them the flexibility of reproducing at any cycle, and this capability may produce no difference in mate-searching activity in the food-enriched environment (Christy \& Salmon 1991, Yamaguchi 1998).

Acknowledgements. We thank the Smithsonian Tropical Research Institute, the Naos Laboratories, and the Culebra Nature Center for financial and logistical support. We are also grateful to Sanha Kim, Byunghyuk Kim, June Lee, and Taekeun Kim for discussion of the manuscript. T.W.K. was supported by a short-term fellowship from STRI and by Korean Research Foundation Grants funded by the Korean Government (MOEHRD) (KRF-2006-351-C00044). T.W.K. is also grateful to the Hopkins Marine Station of Stanford University for supporting him during the publication of this study. J.C.C. was supported by a grant from Ewha Womans University. Thanks are also due to the Amore Pacific Research and Cultural Foundation for financial support.

\section{LITERATURE CITED}

Alexander RD, Marshall DC, Cooley JR (1997) Evolutionary perspective on insect mating. In: Choe JC, Crespi BJ (eds) The evolution of mating system in insects and arachnids. Cambridge University Press, Cambridge, p 4-31

Alexandre A, Cabaco S, Santos R, Serrao EA (2006) Timing and success of reproductive stages in the seagrass Zostera noltii. Aquat Bot 85:219-223

Backwell PRY, Jennions MD, Christy JH, Schober UM (1995) Pillar building in the fiddler crab Uca beebei: evidence for a condition-dependent ornament. Behav Ecol Sociobiol 36:185-192

Brodmann P, Reyer HU, Bollmann K, Schlaepfer AR, Rauter C (1997) The importance of food quantity and quality for reproductive performance in alpine water pipits (Anthus spinoletta). Oecologia 109:200-208

Brommer JE, Merila J, Kokko H (2002) Reproductive timing and individual fitness. Ecol Lett 5:802-810

Christy JH (1978) Adaptive significance of reproductive cycles in the fiddler crab Uca pugilator: a hypothesis. Science 199:453-455

Christy JH (1982) Burrow structure and use in the sand fiddler crab, Uca pugilator (Bosc). Anim Behav 30:487-494

Christy JH (2003) Reproductive timing and larval dispersal of intertidal crabs: the predator avoidance hypothesis. Rev Chil Hist Nat 76:177-185

Christy JH (2007) Predation and the reproductive behavior of fiddler crabs (genus Uca) In: Duffy JE, Thiel M (eds) Evolutionary ecology of social and sexual systems: crustaceans as model organisms. Oxford University Press, New York, p 211-248

Christy JH, Salmon M (1991) Comparative studies of reproductive behavior in mantis shrimps and fiddler crabs. Integr Comp Biol 31:329-337

Christy JH, Schober UM (1994) A test for resource-defense mating in the fiddler crab Uca beebei. Anim Behav 48: 795-802

Christy JH, Backwell PRY, Goshima S (2001) The design and production of a sexual signal: hoods and hood building by male fiddler crabs Uca musica. Behaviour 138:1065-1083

Christy JH, Backwell PRY, Goshima S, Kreuter T (2002) Sexual selection for structure building by courting male fiddler crabs: an experimental study of behavioral mechanisms. Behav Ecol 13:366-374

Christy JH, Baum JK, Backwell PRY (2003) Attractiveness of sand hoods built by courting male fiddler crabs, Uca musica: test of a sensory trap hypothesis. Anim Behav 66:89-94

Cohen D (1976) The optimal timing of reproduction. Am Nat 110:801-807

Cotton S, Fowler K, Pomiankowski A (2004) Do sexual ornaments demonstrate heightened condition-dependent expression as predicted by handicap hypothesis? Proc Biol Sci 271:771-783

Davis SE, Nager RG, Furness RW (2005) Food availability affects adult survival as well as breeding success of parasitic jaegers. Ecology 86:1047-1056

> deBruyn AMH, Meeuwig JJ (2001) Detecting lunar cycles in marine ecology: periodic regression versus categorical ANOVA. Mar Ecol Prog Ser 214:307-310

deRivera CE (2003) Causes of a male-biased operational sex ratio in the fiddler crab, Uca crenulata. J Ethol 21:137-144

> Diaz M, Alonso CL (2003) Wood mouse Apodemus sylvaticus winter food supply: density, condition, breeding and parasite. Ecology 84:2680-2691

Ims RA (1990) The ecology and evolution of reproductive synchrony. Trends Ecol Evol 5:135-140

Iwasa Y, Pomiankowski A, Nee S (1991) The evolution of costly mate preferences. II. The handicap principle. Evolution 45: 1431-1442

> Kim TW, Choe JC (2003) The effect of food availability on the semilunar courtship rhythm in the fiddler crab Uca lactea (de Haan) (Brachyura: Ocypodidae). Behav Ecol Sociobiol 54:210-217

Kim TW, Kim KW, Srygley RB, Choe JC (2004) Semilunar courtship rhythm of the fiddler crab Uca lactea in a habitat with great tidal variation. J Ethol 22:63-68

Kim TW, Sakamoto K, Henmi Y, Choe JC (2008) To court or not to court: reproductive decisions by male fiddler crabs 
in response to fluctuating food availability. Behav Ecol Sociobiol 62:1139-1147

Knowlton N (1979) Reproductive synchrony, parental investment, and the evolutionary dynamics of sexual selection. Anim Behav 27:1022-1033

Kokko H, Jennions M (2003) It takes two to tango. Trends Ecol Evol 18:103-104

Makino W, Ban SH (2000) Response of life history traits to food conditions in a cyclopoid copepod from an oligotrophic environment. Limnol Oceanogr 45:396-407

Morgan SG, Christy JH (1994) Plasticity, constraint, and optimality in reproductive timing. Ecology 75:2185-2203

Morgan SG, Christy JH (1995) Adaptive significance of the timing of larval release by crabs. Am Nat 145:457-479

Mysterud A, Bonenfant C, Loe LE, Langvatn R, Yoccoz NG, Stenseth NC (2008) The timing of male reproductive effort relative to female ovulation in a capital breeder. J Anim Ecol 77:469-477

Niehoff B (2004) The effect of food limitation on gonad development and egg production of the planktonic copepod Calanus finmarchicus. J Exp Mar Biol Ecol 307: 237-259

Nielsen JT, Møller AP (2006) Effects of food abundance, density and climate change on reproduction in the sparrowhawk Accipiter nisus. Oecologia 149:505-518

Palmer JD (1995) The biological rhythms and clocks of intertidal animals. Oxford, New York

Reinsel KA, Glas PS, Rayburn JR, Pritchard MK, Fisher WS (2001) Effects of food availability on survival, growth, and reproduction of the grass shrimp Palaemonetes pugio: a laboratory study. Mar Ecol Prog Ser 220:231-239

Robertson DR, Peterson CW, Brawn JD (1990) Lunar reproductive cycles of benthic brooding reef fishes: reflections of larval biology or adult biology? Ecol Monogr 60:311-329

Rubenstein DR, Wikelski M (2003) Seasonal changes in food quality: a proximate cue for reproductive timing in marine iguanas. Ecology 84:3013-3023

Shultz MT, Piatt JF, Harding AMA, Kettle AB, Van Pelt TI (2009) Timing of breeding and reproductive performance in murres and kittiwakes reflect mismatched seasonal prey dynamics. Mar Ecol Prog Ser 393:247-258

Shuster SM, Wade MJ (2003) Mating systems and strategies. Princeton University Press, Princeton, NJ

Siikamäki P (1998) Limitation of reproductive success by food availability and breeding time in pied flycatchers. Ecology 79:1789-1796

Skov MW, Hartnoll RG, Ruwa RK, Shunula JP, Vannini M, Cannicci S (2005) Marching to a different drummer: crabs synchronize reproduction to a 14 -month lunar-tidal cycle. Ecology 86:1164-1171

Sletvold N, Grindeland JM (2007) Fluctuating selection on reproductive timing in Digitalis purpurea. Oikos 116:473-481

Svensson ES, Nilsson JA (1995) Food supply, territory quality, and reproductive timing in the blue tit (Parus Caeruleus). Ecology 76:1804-1812

Sydeman WJ, Penniman JF, Penniman TM, Pyle P, Ainley DG (1991) Breeding performance in the western gull: effects of parental age, timing of breeding and year in relation to food availability. J Anim Ecol 60:135-149

Trivers R (1972) Parental investment and sexual selection In: Campbell B (ed) Sexual selection and the descent of man. Aldine de Gruyter, Chicago, IL, p 136-179

Varpe O, Jorgensen C, Tarling GA, Fiksen O (2007) Early is better: seasonal egg fitness and timing of reproduction in a zooplankton life-history model. Oikos 116:1331-1342

Weatherhead PJ (2005) Effects of climate variation on timing of nesting, reproductive success, and offspring sex ratios of red-winged blackbirds. Oecologia 144:168-175

Yamaguchi T (1998) Longevity of sperm of the fiddler crab Uca lactea (De Haan, 1835) (Decapoda, Brachyuran, Ocypodidae). Crustaceana 71:712-713

Yoneda M, Wright PJ (2005) Effects of varying temperature and food availability on growth and reproduction in first-time spawning female Atlantic cod. J Fish Biol 67:1225-1241

Zahavi A (1977) The cost of honesty (further remarks on the handicap principle). J Theor Biol 67:603-605

Zar JH (1999) Biostatistical Analysis, 4th edn. Prentice Hall, Upper Saddle River, NJ

\section{Appendix}

Table A1. Uca terpsichores. Repeated measures ANOVA results for experimental treatment effect on the proportion of waving males

\begin{tabular}{|lrrrc|}
\hline Source & MS & df & \multicolumn{1}{c|}{$F$} & $\mathrm{p}$ \\
\hline First trial & & & & \\
Within plots & & & & \\
$\quad$ Day & 2.107 & 24 & 27.216 & $<0.0001$ \\
$\quad$ Day $\times$ Food treatment & 0.193 & 48 & 2.495 & $<0.0001$ \\
$\quad$ Error & 0.077 & 360 & & \\
Between plots & & & & \\
$\quad$ Food treatment & 2.433 & 2 & 10.787 & 0.001 \\
$\quad$ Error & 3.384 & 15 & & \\
$\quad$ & & & & \\
Second trial & & & & \\
Within plots & 0.480 & 25 & 8.148 & $<0.0001$ \\
$\quad$ Day & 0.068 & 50 & 1.164 & 0.221 \\
$\quad$ Day $\times$ Food treatment & 0.058 & 300 & & \\
$\quad$ Error & & & & \\
Between plots & 1.916 & 2 & 6.625 & 0.012 \\
$\quad$ Food treatment & 0.289 & 12 & & \\
$\quad$ Error & & & & \\
\hline
\end{tabular}

Table A2. Uca terpsichores. Repeated measures ANOVA results for experimental treatment effect on the proportion of mate-searching females

\begin{tabular}{|c|c|c|c|c|}
\hline Source & MS & df & $F$ & $\mathrm{p}$ \\
\hline \multicolumn{5}{|l|}{ First trial } \\
\hline \multicolumn{5}{|l|}{ Within plots } \\
\hline Day & 0.620 & 23 & 6.984 & $<0.0001$ \\
\hline Day $\times$ Food treatment & 0.141 & 46 & 1.593 & 0.011 \\
\hline Error & 0.087 & 345 & & \\
\hline \multicolumn{5}{|l|}{ Between plots } \\
\hline Food treatment & 0.369 & 2 & 1.122 & 0.352 \\
\hline Error & 2.465 & 15 & & \\
\hline \multicolumn{5}{|l|}{ Second trial } \\
\hline \multicolumn{5}{|l|}{ Within plots } \\
\hline Day & 0.240 & 24 & 3.522 & $<0.0001$ \\
\hline Day $\times$ Food treatment & 0.067 & 48 & 0.994 & 0.489 \\
\hline Error & 0.068 & 360 & & \\
\hline \multicolumn{5}{|l|}{ Between plots } \\
\hline Food treatment & 0.027 & 2 & 0.052 & 0.949 \\
\hline Error & 3.849 & 15 & & \\
\hline
\end{tabular}

